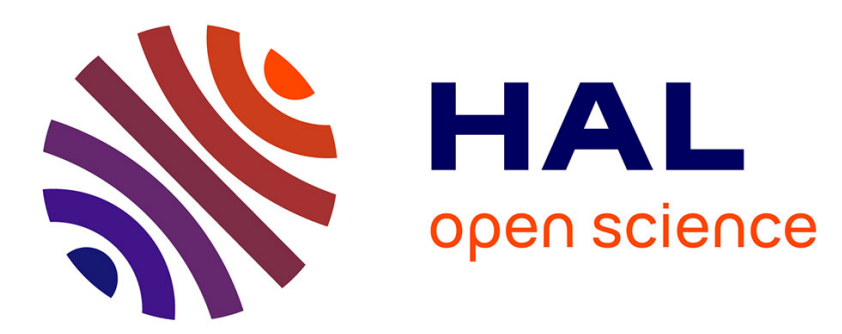

\title{
Can natural disasters have positive consequences? Investigating the role of embodied technical change
}

Stéphane Hallegatte, Patrice Dumas

\section{To cite this version:}

Stéphane Hallegatte, Patrice Dumas. Can natural disasters have positive consequences? Investigating the role of embodied technical change. Ecological Economics, 2009, 68 (3), pp.777-786. 10.1016/j.ecolecon.2008.06.011 . hal-00719266

\section{HAL Id: hal-00719266 \\ https://hal-enpc.archives-ouvertes.fr/hal-00719266}

Submitted on 7 Apr 2015

HAL is a multi-disciplinary open access archive for the deposit and dissemination of scientific research documents, whether they are published or not. The documents may come from teaching and research institutions in France or abroad, or from public or private research centers.
L'archive ouverte pluridisciplinaire HAL, est destinée au dépôt et à la diffusion de documents scientifiques de niveau recherche, publiés ou non, émanant des établissements d'enseignement et de recherche français ou étrangers, des laboratoires publics ou privés. 


\title{
Can natural disasters have positive
}

consequences? Investigating the role of

\section{embodied technical change}

\author{
Stéphane Hallegatte ${ }^{a, b, *}$ Patrice Dumas ${ }^{a}$ \\ ${ }^{a}$ Centre International de Recherche sur l'Environnement et le Développement, \\ Paris, France \\ ${ }^{\mathrm{b}}$ Ecole Nationale de la Météorologie, Toulouse, France
}

\begin{abstract}
It has been suggested that disasters might have positive economic consequences, through the accelerated replacement of capital. This possibility is referred to as the productivity effect. This effect is investigated using a model with embodied technical change. In this framework, disasters can influence the production level but cannot influence the growth rate, in the same way than the saving ratio in a Solowlike model. Depending on reconstruction quality, indeed, accounting for embodied technical change can either decrease or increase disaster costs, but is never able to turn disasters into positive events. Moreover, a better but slower reconstruction amplifies the short-term consequences of disasters, but pays off over the long-term. Regardless, the productivity effect cannot prevent the existence of a bifurcation when disaster damages exceed the reconstruction capacity, potentially leading to poverty traps.
\end{abstract}

JEL Classification: O11; O41; Q54; Q56

Keywords: Embodied technical change, Natural disasters, Economic impacts.

Preprint submitted to Elsevier Science

13 June 2008 


\section{Introduction}

When a disaster occurs, it has been suggested that destructions can foster a more rapid turn-over of capital, which could yield positive outcomes through the more rapid embodiment of new technologies. This effect, hereafter referred to as the "productivity effect", has been mentioned for instance by AlbalaBertrand (1993), Stewart and Fitzgerald (2001), Okuyama (2003) and Benson and Clay (2004).

Indeed, when a natural disaster damages productive capital (e.g., production plants, houses, bridges), the destroyed capital can be replaced using the most recent technologies, which have higher productivities. Examples of such upgrading of capital are: (a) for households, the reconstruction of houses with better insulation technologies and better heating systems, allowing for energy conservation and savings; (b) for companies, the replacement of old production technologies by new ones, like the replacement of paper-based management files by computer-based systems; (c) for government and public agencies, the adaptation of public infrastructure to new needs, like the reconstruction of larger or smaller schools when demographic evolutions justify it. Capital losses can, therefore, be compensated by a higher productivity of the economy in the event aftermath. This process, if present, could increase the pace of

* Corresponding author: Stéphane Hallegatte. Tel.: 331439473 73, Fax.: 331 439473 70. CIRED, 45bis Av. de la Belle Gabrielle, F-94736 Nogent-sur-Marne, France.

Email address: hallegatte@centre-cired.fr (Stéphane Hallegatte). 
technical change and represent a positive consequence of disasters.

As an empirical support for this idea, Albala-Bertand (1993) examined the consequences of 28 natural disasters on 26 countries between 1960 and 1979 and found that, in most cases, GDP growth increases after a disaster and he attributed this observation, at least partly, to the replacement of the destroyed capital by more efficient one. According to Stewart and Fitzgerald (2001) and Benson and Clay (2004), however, this increase in GDP growth is mainly due to a catching-up effect and to the reconstruction-led Keynesian boom, not to a faster embodiment of new technologies. Benson and Clay (2004) also emphasized the difficulty of implementing new technologies in a post-disaster situation, because of the lack of time and financial capacity.

There are other possibly important channels between disasters and productivity, especially through human capital, migration, research and development funding, or large capital inflows from abroad in the event aftermath. This article, however, only considers the productivity effect as described by Okuyama (2003), namely the role of the early replacement of physical capital. This choice is justified (i) by the attention this mechanism has received in the literature and from practitioners; and (ii) by the prospect that disaster reconstruction could be used to improve the long-term economic situation of countries affected by natural disasters. The other channels will nevertheless be investigated in follow-up research.

To investigate the productivity effect, this article proposes, in Section 2, to add a simple modeling of technical change and of its embodiment through investment to the NEDyM model. This model has already been used to assess disaster consequences in Hallegatte et al. (2007a) and to investigate economic 
dynamics in Hallegatte et al. (2007b). Section 3 then assesses how the productivity effect could be able to influence the economic consequences of a single disaster and of a set of disasters distributed at random in time. In particular, this section discusses the potential impact of disasters on long-term economic growth, and the trade-off between rapidity and quality in the reconstruction process. Then, Section 4 investigates, when the productivity effect is effective, the existence of a bifurcation in GDP losses when the capacity to fund and carry out the reconstruction is inadequate with respect to disaster frequency and intensity. Finally, Section 5 summarizes the results, draw some conclusions about how reconstruction should be managed, and highlights a few pressing research questions.

\section{Technical change modeling}

The NEDyM model is fully described in Hallegatte et al. (2007a), but all equations are given in Appendix A. The natural disaster module is explained in Appendix B where all the corresponding equations are also reproduced.

\subsection{The NEDyM model}

The NEDyM model is based on the Solow growth model (Solow, 1956), but (i) price and wage react with delay to production-demand imbalances and employment disequilibrium and (ii) investment responds to present capital profitability, which depends both on price and demand. Therefore, even though the model has the same balanced growth pathway than a Solow growth model, it can also reproduce short-term Keynesian features when the economy is 
perturbed by a shock like a disaster (see Hallegatte et al., 2007a). This model can, therefore, reproduce under- and over-employment, and reconstruction-led economic growth.

To account for destruction of capital due to disasters (see Appendix B), we measure the capital using two variables instead of one in the Solow model: the potential capital $K_{0}$ and the portion of non-destroyed capital $\xi_{K}$ : the actual amount of capital $K$ is given by $K=\xi_{K} K_{0}$. Also, we introduce two types of investments: the production investments $I_{n}$, which aim at increasing production capacity in absence of disaster and increase $K_{0}$, and the reconstruction investments $I_{r}$, which are carried out when a disaster has caused damages and make the portion of non-destroyed capital $\xi_{K}$ return to one. In this model, investments increase after disasters in response to the increase in capital profitability caused by capital destructions. To account for important financial and technical constraints in the reconstruction process (see Benson and Clay, 2004), we also introduced a limitation of the reconstruction investments at $f_{\text {max }}=5 \%$ of the total investments $I=I_{n}+I_{r}$, meaning that the economy can mobilize about $1 \%$ of its annual GDP per year for reconstruction tasks:

$$
I_{r} \leq f_{\max } I
$$

Taking into account this constraint is necessary to reproduce the reconstruction dynamics observed after past disasters (Hallegatte et al., 2007a). Details of the disaster modeling are provided in Appendix B.

This model assumes that the only impact of natural disasters is a destruction of productive capital. Labor supply, for instance, is not affected. This assumption is realistic in most but not all cases. After Katrina hit New Orleans, 
for instance, house destructions were so widespread that many workers had to leave the city, modifying the labor market in a significant manner. Representing all consequences of Katrina, therefore, would require to model the migration of the workers leaving the affected area in the immediate disaster aftermath, and those returning to the area when reconstruction begins.

To give a realistic flavour to this highly-idealized model, it is roughly calibrated so that its benchmark equilibrium is the economic balance of the European Union in 2001(EU 15) ${ }^{1}$.

\subsection{Modeling the productivity effect}

A technological change modeling is introduced into the model. This modeling is inspired by the vintage-capital modeling used in Solow (1962) and is based on the productivity difference between the technologies used by the installed capital and the most recent available technologies, which have increasing productivities.

We assume that, at each point in time, the most recent capital has a productivity $A(t)$, which increases exogenously by $2 \%$ per year $^{2}$. This technical progress is assumed to "fall from the sky", and nobody has to pay for it, unlike, for instance, in Aghion and Howitt (1998). The installed capital, on the other hand, is composed of investments made at different points in time, which have different productivities. The installed capital ${ }^{3}$ has, therefore, a mean productivity $\Lambda(t)$, which is lower that $A(t)$. When new investments are carried out, using the newest technologies, $\Lambda(t)$ increases, making the whole economy more productive. This embodied technical progress is found to explain most 
of the observed growth in productivity (see Jorgensen and Griliches, 1967; or Greenwood et al., 1997).

In our Solow-like growth framework, we model in a very simple way the evolution of $\Lambda(t)$ as a function of $A(t)$ and of the current amount of investments. To do so, we consider a first economy, characterized by an amount of labor $L_{1}$ and an amount of productive capital $K_{1}$ of homogeneous productivity $A_{1}$. The Cobb-Douglas production function of NEDyM gives then the production $Y_{1}$ of this economy:

$$
Y_{1}=A_{1} L_{1}^{\alpha} K_{1}^{1-\alpha}
$$

A second economy is characterized by an amount of labor $L_{2}$ and a capital $K_{2}$ of homogeneous productivity $A_{2}$, with $A_{2}>A_{1}$. The corresponding production is:

$$
Y_{2}=A_{2} L_{2}^{\alpha} K_{2}^{1-\alpha}
$$

If the labor/capital ratio is the same in both economy (i.e. $L_{1} / K_{1}=L_{2} / K_{2}=$ $\nu)$, then the economy created by merging both economies is characterized by labor $L=L_{1}+L_{2}$ and capital $K=K_{1}+K_{2}$, and a mean productivity $\Lambda$. Since $Y=Y_{1}+Y_{2}$, we have:

$$
\overbrace{\Lambda L^{\alpha} K^{1-\alpha}}^{\Lambda \nu K}=\overbrace{A_{1} L_{1}^{\alpha} K_{1}^{1-\alpha}}^{A_{1} \nu K_{1}}+\overbrace{A_{2} L_{2}^{\alpha} K_{2}^{1-\alpha}}^{A_{2} \nu K_{2}},
$$

which means:

$$
\Lambda=\frac{K_{1} A_{1}+K_{2} A_{2}}{K_{1}+K_{2}}
$$

The mean productivity $\Lambda$ of a set of different homogeneous capitals of pro- 
ductivity $A_{i}$ is the weighted average of the capital productivities.

We can now apply this to the investment/depreciation equation: the productive capital at one time $t, K_{t}$, is constituted by a part $\left(1-1 / \tau_{d e p}\right)$ of the previous year productive capital $K_{t-1}$, that have a mean productivity $\Lambda_{t-1}$; and by an amount $I_{t}$ of the most recent productive capital, that has a productivity $A_{t}$. As a consequence, the mean productivity of the capital is equal to the weighted average of the previous year capital mean productivity and of the most recent capital one:

$$
\Lambda_{t}=\frac{I_{t} A_{t}+\left(1-\frac{1}{\tau_{d e p}}\right) K_{t-1} \Lambda_{t-1}}{I_{t}+\left(1-\frac{1}{\tau_{d e p}}\right) K_{t-1}}=\frac{I_{t} A_{t}+\left(1-\frac{1}{\tau_{d e p}}\right) K_{t-1} \Lambda_{t-1}}{K_{t}}
$$

This modeling is a simplified version of the Solow's (1962) modeling of embodied technical change. Also, the product $\Lambda(t) K(t)$ is a proxy for the Solow's "equivalent stock of capital". One shortcoming of our modeling, compared with Solow's, is that depreciation is here assumed to affect capital independently of its productivity. This feature amount to assume, not quite unrealistically, that each capital vintage is constituted of a set of capital goods whose scrapping times are uniformly distributed from zero (e.g., small equipment) to infinity ${ }^{4}$ (e.g., large infrastructure, urban structure).

Rewriting Eq.(6) in continuous time, we get:

$$
\frac{d \Lambda_{t}}{d t}=\frac{I_{t}}{K_{t}}\left(A_{t}-\Lambda_{t}\right)
$$

that describes the evolution of the mean capital productivity, as a function of (i) the productivity of the most recent capital; (ii) the current-capital mean productivity; (iii) the amount of investment, compared with the amount of installed capital. 
In such a modeling, if a disaster forces to replace one part of the capital, the new mean productivity is higher than the previous one. This modeling of the productivity effect, however, represents only the most optimistic possibility, in which all capital replacement is carried out embodying the most recent technologies. Past experiences, however, do not fully support this assumption. The following section proposes a modeling of a more realistic productivity effect.

\subsection{Discussion of the realism of the productivity effect}

The productivity effect is probably not fully effective, for several reasons. First, when a disaster occurs, producers have to restore their production as soon as possible. This is especially true for small businesses, which cannot afford long production interruptions (see Kroll et al., 1991 or Tierney, 1997), and in poor countries, in which people have no mean of subsistence while production is interrupted. Replacing the destroyed capital by the most recent type of capital implies in most cases to adapt company organization and worker training, which takes time. Producers have thus a strong incentive to replace the destroyed capital by the same capital, in order to restore production as quickly as possible, even at the price of a lower productivity.

Second, even when destructions are quite extensive, they are never complete. Some part of the capital can, in most cases, still be used, or repaired at lower costs than replacement cost. In such a situation, it is possible to save a part of the capital if, and only if, the production system is reconstructed identical to what it was before the disaster. This technological "inheritance" acts as a major constraint to prevent a reconstruction based on the most recent 
technologies and needs, especially in the infrastructure sector.

Third, our modeling assumed a constant growth of the best technology productivity. In a framework that explicitly model this productivity rise, based on Research and Development (R\&D) for instance, the resources used by the reconstruction after a disaster could have to be removed from the R\&D process, slowing down the technological progress. In this case, the overall effect would be a slowing down of the productivity growth, in spite of the more rapid turnover of capital.

As a consequence of these caveats, our modeling of the productivity effect represents the most optimistic situation, which is theoretically possible, and the corresponding positive outcomes represent the upper bound of the possible outcomes.

\subsection{Modeling an imperfect productivity effect}

There are some evidences that, at least, all the reconstruction cannot be carried out incorporating the newest technologies. To model an imperfect productivity effect, we make use of the distinction between production investments $I_{n}$ and reconstruction investments $I_{r}$. In our modeling of imperfect embodiment of technical change, we assume that only one fraction $\chi$ of the reconstruction investment participates in the embodiment of new technologies. This is done by rewriting Eq.(7) as:

$$
\frac{d \Lambda_{t}}{d t}=\frac{I_{n}+\chi I_{r}}{K}\left(A_{t}-\Lambda_{t}\right)
$$


If $\chi=1$, the reconstruction is carried out using the most recent technology and the productivity effect is fully effective (this is equivalent to the perfectproductivity-effect described in the previous section). If $\chi=0$, the reconstruction is carried out using the same technologies that the capital that has just been destroyed. In this case, the reconstruction following the disaster does not accelerate the embodiment of new technologies and does not increase productivity growth. On the opposite, since disasters force some part of investment to be devoted to reconstruction investments instead of production investments, they slow down the embodiment of new technologies.

\section{The influence of the productivity effect}

This section assesses the influence of the perfect and imperfect productivity effects on the economic consequences of disasters. To assess the role of the productivity effect, we reproduce with the various versions of our model the consequences of a disaster that destroys an amount of productive capital of $2.5 \%$ of GDP.

\subsection{The baseline scenario}

To compare the consequences of this disaster when the embodiment of technical change in capital is taken into account and when technical change is exogenous, we create a model in which the mean productivity rise is constant, by rewriting Eq.(7) as:

$$
\frac{d \Lambda_{t}}{d t}=\frac{I_{r e f}}{K_{r e f}}\left(A_{t}-\Lambda_{t}\right)
$$


where $I_{r e f} / K_{\text {ref }}$ is the ratio of investment to installed productive capital along the balanced growth pathway of the model, when no disaster occur. The model based on Eq.(9) is referred to as $E X$; its productivity growth is exogenously fixed and there is no productivity effect.

The model with endogenous technical change and perfect productivity effect, based on Eq.(7), is referred to as $E N$; its productivity growth depends on the amount of investment and all reconstruction investments use the most recent technologies. The model with endogenous technical change and imperfect productivity effect, based on Eq.(8), is referred to as $I M-\chi$; its productivity growth depends on the amount of investment and only a fraction $\chi$ of reconstruction investments is carried out with the most recent technologies.

All these models have the same balanced growth pathway when no disaster occurs, i.e. they have the same baseline.

\subsection{The impacts of the productivity effect}

In this section, only three hypotheses are represented: exogenous technical change (EX); endogenous technical change with perfect productivity effect (EN); and endogenous technical change with the most pessimistic imperfect productivity effect (i.e., with $\chi=0)($ IM-0). Investigating the perfect productivity effect and the most inefficient imperfect productivity effect allows to bound the possible influence of the productivity effect in spite of the uncertainty on its efficiency.

[Fig. 1 about here.] 
The upper panel of Fig. 1 shows that the perfect productivity effect leads to a small reduction in productivity growth during the year following the disaster. This reduction arises from the reduction in investment due to the decrease in production. But after one year, the larger amount of investments needed for the reconstruction process makes productivity growth rise, and the productivity effect produces then positive outcomes.

The bottom panel of Fig. 1 shows that, when the productivity effect is perfectly effective, the scenario with disaster has a larger production than in the scenario without disaster, but this absolute positive effect is very small, showing that there is little ground to assume that natural disaster can have an absolute positive impact on the economy. At best, the productivity effect can reduce the negative consequences of disasters, but it can hardly make disasters yield overall positive consequences.

Moreover, the imperfect productivity effect (with $\chi=0$ ) amplifies the disaster negative consequences. Indeed, in this hypothesis, reconstruction is carried out using the already installed technologies, not the most recent ones. Since reconstruction investments have a crowding-out effect on production investments, which drive the embodiment of new technologies, reconstruction here limits this embodiment and, therefore, reduces the rate of productivity growth. In our modeling exercise with the IM-0 hypothesis, productivity growth is reduced by $0.1 \%$ during almost 2 years, which has a significant (but small in absolute terms) impact on production: both the short-term and medium-term production losses are larger than in the EX or EN cases.

Negative consequences are also observed in response to a set of disasters, as can be seen in Fig. 2. The perfect productivity effect EN allows for a canceling 
of the averaged GDP losses. Again, however, potential absolute positive effect are small and the productivity effect is able to reduce the cost of disasters, but unable to turn disasters into positive events. However, the imperfect productivity effect IM-0 leaves the average losses almost unchanged compared with the exogenous technical change hypothesis EX, even though it amplifies each of the shocks and increases their duration.

[Fig. 2 about here.]

In the imperfect productivity effect hypothesis with $\chi=0$, therefore, endogenous technical change amplifies the cost of disasters over all timescales, instead of reducing it like in the perfect productivity effect.

\subsection{Consequences on long-term growth}

An important research question is whether natural disasters can have an impact on long-term economic growth. This question has been investigated empirically by, e.g., Albala-Bertrand (1993), Benson (2003), and Skidmore and Toya (2002), but results are not conclusive. Albala-Bertrand (1993) found, in a statistical analysis of 28 disasters from 1960 to 1976 in 26 countries, that the long-run growth rate (like the other macroeconomic variables) is unaffected by natural disasters. Benson (2003) carried out an analysis on 115 countries and found that the 1960-to-1993 growth rate was lower in the countries that experienced more disasters. The analysis of Skidmore and Toya (2002), finally, suggests that weather disasters (as opposed to geologic disasters) have a positive influence on capital accumulation and long-term economic growth.

The analysis presented here suggests that, in a Solow-like macroeconomic 
framework with endogenous growth, disasters cannot increase economic growth. Indeed, even with the most optimistic EN assumption, disasters only bring the economy closer to the technological frontier, therefore increasing economic production with respect to a scenario without disasters, but they cannot increase economic growth rate, because the growth rate is only determined by technological change. This result, in fact, is a transposition of the classical Solow result regarding the saving rate: a larger saving rate increases the level of production, not the growth rate. The same is true with disasters: more disasters make the productive capital be more recent and more efficient, thus increasing the level of production, but the long-term growth rate remains unchanged: two economies cannot diverge because of the accelerated capital turn-over due to disasters.

In this framework, therefore, disasters can influence the short-term growth rate, in the few years following each disaster, and the long-term production level, but cannot influence the long-term growth rate.

\subsection{The quality-speed trade-off}

It is likely, however, that the real world is somewhere between the very optimistic EN assumption of perfect productivity effect, with $\chi=1$, and the very pessimistic IM assumption of imperfect productivity effect, with $\chi=0$.

Reconstruction exhibits, classically, two phases: (i) the restoration of basic services (e.g., water and energy delivery, restoration of transportation possibilities, emergency housing), which can hardly take into account other factors than urgency; and (ii) the reconstruction of other damages (e.g., infrastructure 
reconstruction, building and plant reconstruction). At least some embodiment of new technologies can be carried out during the second phase.

Ensuring that this embodiment takes place, however, is likely to make the reconstruction process much slower than it could be otherwise. A slower reconstruction means a larger amount of lost production, and therefore a larger direct cost of the disaster. But this larger cost could be compensated by the productivity gains yielded by the embodiment of new technologies. These two contradictory effects suggest the existence of a trade-off between the quality and speed of the reconstruction. The quality of the reconstruction can be measured by the amount of embodiment of new technologies in reconstruction, i.e. by $\chi$. The pace of reconstruction can be measured by the limits to reconstruction $f_{\text {max }}$, since it constraints the maximum amount of reconstruction investments that can be made at one point in time (see Eq. (1)).

To investigate the quality-speed trade-off, we assume a very simple relationship between $f_{\max }$ and $\chi$. In our first model version, $f_{\max }$ represented the financial and technical capacity to fund and carry out the reconstruction. In this new version, $f_{\text {max }}$ depends also on the reconstruction quality, i.e. on the embodiment of new technologies. We introduce, therefore, the relationship:

$$
f_{\max }=f_{\max }^{0} \frac{1}{1+(\gamma-1) \chi}
$$

where $f_{\max }^{0}$ is the maximum amount of reconstruction investments that can be carried out if the reconstruction is made identical to the destroyed capital. In the following, we assume that $\gamma=2$, which means that a "high-quality" reconstruction, which would use only the most recent technologies, is able 
to mobilize, at one point in time, only one half of the amount of investments that a "low-quality" reconstruction based on unchanged technologies is able to mobilize. This modeling is referred to, for each value of $\chi$, as the quality-speed trade-off modeling (QS- $\chi)$.

[Fig. 3 about here.]

Figure 3 shows that, over the short-term and when coping with a single event, the negative impact of a slower reconstruction - due to a lower $f_{\max }$ - exceeds the positive impact of a better embodiment of new technologies during reconstruction. The shock due to the disaster is deeper and longer as $\chi$ increases. Over the medium-term, however, the embodiment of new technologies yields significant gain in production. Over the long-term, when coping with a series of disasters, Fig. 4 shows that the long-run average GDP losses decreases as $\chi$ increases, even though each shock is stronger. The simulations with hypotheses EN and QS with $\chi=1$ can hardly be distinguished, confirming a finding of Hallegatte et al. (2007a): as long as the bifurcation in losses is not reached (see Section 4 below), average GDP losses are quite insensitive to the short-term constraints modeled through $f_{\max }$, even though the influence of these constraints can be large during the few years following each disaster.

[Fig. 4 about here.]

Interestingly, all these results are unchanged if $\gamma$ is equal to 10 instead of 2 , even though the timescale for which the positive effect exceeds the negative one is much longer (not shown). This hypothesis with $\gamma=10$ is very pessimistic, since it means that, in order to embody new technologies in all reconstructions, the maximum amount of reconstruction investments at one point in time has to be divided by 10 compared with a "low-quality" reconstruction. Our findings, 
therefore, are robust even for very pessimistic values of $\gamma$.

These results yield two important conclusions. First, the trade-off between the

speed and the quality of the reconstruction can be re-phrased as a trade-off between short-term and long-term consequences. A slower and better reconstruction amplifies the short run consequences of a disaster, but it allows for a quasi-canceling of the long-run consequences of the disasters.

\section{Bifurcation and poverty traps}

In Hallegatte et al. (2007a), disaster-related losses were found to depend strongly and non-linearly both on the characteristics of the disaster distribution and on the economic ability to fund and carry out the reconstruction after each disaster (through the variable $f_{\max }$ in the model). In particular, a bifurcation in GDP losses appears when disasters are more frequent or more intense than a threshold value, which depends on the reconstruction capacity $f_{\max }$.

Using the most optimistic assumption, the perfect productivity effect modeling EN, the bifurcation still exists in the model. More precisely, Fig. 5 shows the average GDP losses (over 200 years) due to disasters, in the $E X$ and $E N$ scenarios, as a function of the probability and intensity of the extreme events. In each simulation, the probability and the mean cost of the disasters are multiplied by $\alpha$ with respect to the observed distribution. $f_{\max }$ is always at $5 \%$.

[Fig. 5 about here.] 
For a wide range of disaster distribution parameters, approximately when $\alpha$ is in the range $[0: 5]$, GDP losses are increasing linearly with $\alpha$ in the $E X$ case, from approximately 0 to $1.5 \%$ of GDP, while they remain negligible in the EN case. Within this range, the productivity effect - fully effective - is able to compensate the direct losses due to the shocks.

But, when $\alpha$ gets larger than a threshold value, i.e. when the probability and the mean cost of the extremes are multiplied by more than this value (here approximately 5), the GDP losses increase rapidly in both modeling, to reach $100 \%$ for $\alpha \approx 7.2$.

The position of the bifurcation is not affected by the introduction of the productivity effect in the model. This independence is explained by the fact that the bifurcation arises from a mechanism that is quite insensitive to the presence of the productivity effect. When reconstruction capacity is too low, indeed, the economy is unable to rebuild totally between each disaster and the economy remains in a perpetual stage of reconstruction. In such a situation, the productivity effect becomes negligible compared with the disaster losses in terms of lost production.

Moreover, this poverty trap effect can be accelerated by three processes. First, it has been observed that disasters can lead to significant migrations. If skilled workers, who have the financial means to move and settle down in other regions, leave the affected region in the disaster aftermath and do not return during and after reconstruction, then the human capital loss of the disaster can largely exceed all impacts on productive capital. After Katrina, for instance, many workers in the health care sector left New Orleans and did not return, impairing the economic recovery of the city (see Eaton, 2007). Second, 
even when no disaster occurs, disaster risks can represent a disincentive to invest over the long term. This disincentive may have a negative impact on economic growth, even in absence of actual destructions. Finally, if disaster reconstruction has an eviction effect on research, development, and innovation efforts, the growth rate of the most recent technologies could slow down, thereby reducing economic growth. Today, however, the impact of a local disaster on the development of new technologies is likely to remain limited and this mechanism is unlikely to have a significant impact on poverty traps.

Of course, this explanation for poverty traps is only valid in the least developed economies, where production capacity is low. In developed countries, which have more economic resources, large GDP losses can be avoided through an increase in $f_{\max }$, i.e. through an adaptation of the economy to make it more efficient in funding and carrying out the reconstruction after each disaster. For instance, it is likely that the number of roofers in Florida is larger than in other U.S. states, because frequent hurricanes provide work for them. Also, specific insurance schemes (e.g., the Florida Disaster Recovery Fund) are present in regions where risks are large, to insure that affected population and businesses can restore their activity after each event. The $f_{\max }$ parameter, therefore, is likely to be larger in Florida than in other states, preventing very high GDP losses in spite of the large exposure to hurricanes. Our explanation for poverty traps, therefore, apply only in countries where the capacity to fund and carry out the reconstruction is not adapted to the level of natural risks, which may happen for various economic or political reasons. 


\section{Conclusion}

The conclusions drawn from these simple modeling exercises do not contradict previous results. With or without productivity effect, short-term constraints on reconstruction have a large influence on the deepness and duration of the negative consequences of a disaster. Over the long-term, these constraints do not play any role and disasters do not influence the long-term growth rate, unless the capacity to fund and carry out the reconstruction is lower than a threshold value, related to the intensity and frequency of disasters. In this latter case, short-term constraints can create poverty traps, in which the long-run GDP losses due to disasters can reach very high values, preventing economic development. With or without productivity effect, therefore, it is essential to ensure that, in any economy, the capacity to fund and carry out reconstruction is adapted to the level of disaster risk.

Natural disasters may thus be an explanation for poverty traps, in addition to other factors mentioned in the literature; see a review in Azariadis (1996). It is well known that climate is a important driver of economic growth in some countries, especially from the developing world where agriculture constitutes a significant sector of the economy (e.g., Bloom et al., 2003). But these analyses account only for mean climatic conditions (mean temperature, mean precipitation, seasonal patterns). Our results suggest that extreme events and natural disasters need also to be considered ${ }^{5}$.

In our model, when the economy is far from the disaster-related poverty trap, it is found that the productivity effect has a significant impact on the production level since, when effective, it can cancel the long-run losses due to disasters. 
It is unable, however, to increase the long-term growth rate, which is only determined by technological innovation.

Because of its influence on the long-term production level, there is, however, a strong incentive to implement policies able to ensure that the productivity effect is, at least partly, effective. To do so, it is necessary to help economic agents to improve the quality of the reconstruction, even at the expense of the speed of reconstruction. This is possible, provided that:

(1) Disaster aid, through government-funded schemes or insurance-based scheme, is made available for an extended period of time, to allow affected businesses and individuals to design and implement reconstruction strategies that take into account the most recent technologies. Such reconstruction strategies are longer to undertake than recreating an identical production system. Affected agents, therefore, would carry it out only if they have an alternative source of income during reconstruction. Such strategies can yield positive outcomes over the long run, in spite of their short-term costs.

(2) Recovery and reconstruction plans, which are now created and maintained in most companies and institutions, should take into account new needs and technologies, to allow for a "smarter" reconstruction in spite of the urgency in disaster aftermaths. Such plans are needed at the business, regional and national scale. Since, in most cases, there is no time to carry out extensive analyzes of demand evolution or potential infrastructure and production systems upgrades, this work should rather be done before the disaster occurs.

These results are somewhat sensitive to the modeling framework that has been 
used. It seems, however, that these findings are quite robust and does not depend on the chosen macro-economic model framework. In particular, these results would remain valid in the classical Solow model where disequilibrium processes are not represented. The productivity effect, indeed, is essentially related to the - very classical — technical change module. Changes in production function or investment dynamics should not modify the relative influence of the productivity effect, even though the absolute response of the model could be modified. In the same way, large capital inflows would not change the possible influence of earlier capital replacement, since this effect does not depend on where the capital comes from. Moreover, capital availability is not a binding constraint in the model, making the question of international capital flows secondary.

Other mechanisms, however, could influence in a larger manner disaster aftermath. Most importantly, this article does not investigate all potential channels between natural disasters and long-term growth and there are several important limitations in our modeling framework. First, the productivity of the most recent capital is assumed to increase at a constant rate, and the production of technical change through education, learning by doing, and research and development was not considered (see Aghion and Howitt, 1998). In particular, the inclusion of technological change modeling may have different consequences in developed countries, where the economy is at the technological frontier and new technologies have to be developed, and in developing countries, where technologies are mostly imported from abroad. Future research should focus on this aspect. Second, several impacts of disasters were disregarded, like migrations, disruptions of social networks and violent conflicts, which could affect human capital and, therefore, productivity. Miguel et al. (2004), for instance, 
showed in a panel of 41 African countries, that extreme rainfall variations leading to negative growth shocks increase the likelihood of conflicts (by 50 percent for a -5 percent growth rate shock). Obviously, violent conflicts have then important consequences on economic development and should be taken into account. Third, disasters have important consequences at the micro-level that can have aggregated macroeconomic impacts. For instance, Carter et al. (2006) show how disasters in Ethiopia (drought) and Honduras (hurricane) have pushed numerous poor households in poverty traps, leading to a permanent state of low productivity and earning. The aggregated impact of these micro-processes has to be taken into account. Finally, it is important to stress that disasters do not have an economic impact only when they occur. Disaster risks, indeed, can represent a significant disincentive to invest in productive capital, thereby reducing economic growth even during periods when no disaster occurs (see, e.g., Elbers and Gunning, 2003). All these processes are important but not well understood, suggesting that important progresses in disaster management could result from more research in this field.

\section{Acknowledgments}

The authors wish to thank Carlo Carraro and Richard Tol, who suggested this paper, and two referees for their helpful comments and remarks. The

remaining errors are entirely the authors'. This research was supported by the European Commission's Project GOCE-CT-2003-505539 "ENSEMBLES”. 


\section{References}

Aghion, P., \& Howitt, P.W. (1998). Endogenous Growth Theory, MIT Press, USA.

Albala-Bertrand, J. M. (1993). The Political Economy of Large Natural Disasters with Special Reference to Developing Countries. Oxford: Clarendon Press.

Azariadis, A. (1996). The economics of poverty traps part one: Complete markets, Journal of Economic Growth, 1(4), 449-486.

Benson, C. (2003). The Economy-wide Impact of Natural Disasters in Developing Countries, Doctoral thesis. University of London.

Benson, C., \& Clay, E. (2004). Understanding the economic and financial impact of natural disasters. The International Bank for Reconstruction and Development. The World Bank, Washington D.C.

Bloom, D.E., Canning, D., \& Sevilla, J. (2003). Geography and povery traps, Journal of Economic Growth, 8(4), 355-378

Carter, M.R., Little, P.D., Mogues, T., \& Negatu, W. (2006). Poverty Traps and Natural Disasters in Ethiopia and Honduras, World development, 35(5), $835-856$.

Eaton, L. (2007). New Orleans recovery is slowed by closed hospitals, The New York Times, July 24, 2007.

Elbers, C., \& Gunning, J. (2003). Growth and Risk: Methodology and Microevidence, Tinbergen Institute Discussion Papers, 03-068/2. 
Fisher, F.M. (1965). Embodied technological change and the existence of an aggregate capital stock, Review of Economic Studies, 32(4), 263-288.

Greenwood, J., Hercowitz, Z., \& Krusell, P. (1997). Long-run implications of investment-specific technological change, The American Economic Review, $87(3), 342-362$.

Hallegatte, S., Hourcade, J.-C., \& Dumas, P. (2007a). Why economic growth dynamics matter in assessing climate change damages: illustration on extreme events, Ecological Economics, in press, preprint available on http://www.centrecired.fr/forum/article77.html?lang=en.

Hallegatte, S., Ghil, M., Dumas, P. \& Hourcade, J.-C. (2007b). Business cycle, bifurcation and chaos in a neoclassical model with investment dynamics, Journal of Economic Behavior and Organization, in press, preprint available on http://www.centre-cired.fr/forum/article320.html?lang=en.

Jorgensen, D.W., \& Griliches, Z. (1967). The explanation of productivity change, Review of Economic Studies, 34, 249-83.

Kroll, C. A., Landis, J. D., Shen, Q., \& Stryker, S. (1991). Economic Impacts of the Loma Prieta Earthquake: A Focus on Small Business. Studies on the Loma Prieta Earthquake, University of California, Transportation Center.

Miguel E., Satyanath, S., \& Sergenti, E. (2004). Economic Shocks and Civil Conflict: An Instrumental Variables Approach. Journal of Political Economy, $112(4), 725-753$.

Munich Re, 2006. Topics. Annual Review: Natural Catastrophes 2005. Munich Reinsurance Group, Geoscience Research Group, Munich, Germany. 
Okuyama, Y. (2003). Economics of natural disasters: a critical review. Research Paper 2003-12, Regional Research Institute, West Virginia University, USA.

Skidmore, M, \& Toya, H. (2002). Do Natural Disasters promote Long-Run Growth ?, Economic Enquiry, 40, 664-688.

Solow, R.M. (1956). A contribution to the theory of economic growth. The Quarterly Journal of Economics, 70(1), 65-94.

Solow, R.M. (1962). Technical progress, capital formation, and economic growth, The American Economic Review, 52(2), Papers and Proceedings of the SeventyFourth Annual Meeting of the American Economic Association (May 1962), $76-86$.

Stewart, F., \& Fitzgerald, E.V.K. (2001). War and Underdevelopment. Oxford: Oxford University Press.

Tierney, K. (1997). Business impacts of the Northridge earthquake. Journal of Continencies and Crisis Management, 5(2), 87-97. 


\section{A Appendix: NEDyM, a Dynamic Model to capture unbalanced growth pathways}

NEDyM (Non-Equilibrium Dynamic Model) is a model that reproduces the behavior of the Solow model over the long term, but allows for disequilibria during transient periods. Full description and analysis of NEDyM are available in Hallegatte et al. (2007a), but all principles and equations are reproduced here.

NEDyM models a closed economy, with one representative consumer, one producer, and one good, used both for consumption and investment. The original Solow (1956) model is composed of a static core describing the market equilibrium and a dynamic relationship describing the productive capital evolution. In NEDyM, we translate the static core into dynamic laws of evolution by building delays into the pathways toward equilibrium. This device introduces short-term dynamics into the model.

We explain below the main changes applied to the basic Solow model, starting with its core set of equations where $Y$ is production; $K$ is productive capital; $L$ is labor; $A$ is total productivity; $C$ is consumption; $S$ is consumer savings; $I$ is investment; $\Gamma_{i n v}$ is the investment (or, equivalently, saving) ratio; $\tau_{d e p}$ is the depreciation time; and $L_{\text {full }}$ is the labor at full-employment:

$$
\begin{aligned}
& \frac{d K}{d t}=I-\frac{K}{\tau_{d e p}}, \\
& Y=f(K, L)=A L^{\lambda} K^{\mu}, \\
& C+I=Y,
\end{aligned}
$$


$L=L_{\text {full }}$,

$S=\Gamma_{i n v} Y$

$I=S$.

NEDyM introduces the following changes to this generic structure:

(1) Goods markets: a goods inventory $\mathrm{H}$ is introduced, opening the possibility of temporary imbalances between production and demand instead of a market clearing at each point in time $(Y=C+I$, Eq. (A.3)):

$$
\frac{d H}{d t}=Y-(C+I)
$$

This inventory ${ }^{6}$ encompasses all sources of delay in the adjustment between supply and demand (including technical lags in producing, transporting and distributing goods). Its situation affects price movements:

$$
\frac{d p}{d t}=-p \cdot\left(\alpha_{\text {price }}^{1} \cdot \frac{Y-(C+I)}{Y}+\alpha_{\text {price }}^{2} \cdot \frac{H}{Y}\right) .
$$

Thus price adjustments operate non-instantaneously and the conventional market clearing conditions are verified only over the long term.

(2) Labor market: the producer sets the optimal labor demand $L_{e}$ that maximizes profits as a function of real wage and marginal labor productivity:

$$
\frac{w}{p}=\frac{d f}{d L}\left(L_{e}, K\right)
$$

But full-employment is not guaranteed at each point in time such as in Eq. (A.4) $\left(L=L_{\text {full }}\right)$ because (i) institutional and technical constraints create a delay between a change in the optimal labor demand and the 
corresponding change in the number of actually employed workers:

$$
\frac{d L}{d t}=\frac{1}{\tau_{e m p l}}\left(L_{e}-L\right) ;
$$

and (ii) wages are partially rigid over the short-term; they progressively restore the full employment rate by increasing (resp. decreasing) if labor demand is higher (resp. lower) than $L_{f u l l}$,

$$
\frac{d w}{d t}=\frac{w}{\tau_{\text {wage }}} \frac{\left(L-L_{\text {full }}\right)}{L_{\text {full }}} .
$$

(3) Household behavior: as the Solow model, NEDyM uses a constant saving ratio but it makes the tradeoff between consumption and saving ( $S=$ $\Gamma_{i n v} Y$, Eq. (A.5)) more sophisticated by considering that households (i) consume $C$, (ii) make their savings available for investment through the savings $S$, and (iii) hoard up a stock of money $M$, that is not immediately available for investment ${ }^{7}$.

(4) Producer behavior: instead of automatically equating investments and savings $(I=S$, Eq. (A.6)), NEDyM describes an investment behavior " $a ̀$ la Kalecki (1937)". It introduces a stock of liquid assets held by banks and companies which is filled by the difference between sales $p(C+I)$ and wages $(w L)$ and by the savings received from consumers $(S)$. These assets are used to redistribute share dividends ${ }^{8}$ (Div) and to invest $(p I)$. This formulation creates a wedge between investment and savings.

$$
\frac{d F}{d t}=p(C+I)-w L+S-D i v-p I
$$

The dynamics of the system is governed by an investment ratio which allocates these assets between productive investments and share dividends:

$$
p I=\Gamma_{i n v} \cdot \alpha_{F} F
$$




$$
D i v=\left(1-\Gamma_{i n v}\right) \cdot \alpha_{F} F .
$$

This ratio is such that the redistributed dividends satisfy an exogenous required return on equity $\rho$ demanded by the shareholders. This describes a specific growth regime under which producers invest the amount of funds available when the required amount of dividends have been paid ${ }^{9}$.

$$
\frac{d \Gamma_{i n v}}{d t}=\left\{\begin{array}{ll}
\alpha_{i n v}\left(\gamma_{\max }-\Gamma_{i n v}\right) \cdot\left(\frac{D i v}{p \cdot K}-\rho\right) & \text { if } \frac{D i v}{p \cdot K}-\rho>0 \\
\alpha_{i n v}\left(\Gamma_{i n v}-\gamma_{\min }\right) \cdot\left(\frac{D i v}{p \cdot K}-\rho\right) & \text { if } \frac{D i v}{p \cdot K}-\rho \leq 0
\end{array} .\right.
$$

The extrema $\gamma_{\min }=0$ and $\gamma_{\max }=0.8$ of $\Gamma_{i n v}$ are parameters that represent, respectively, the positivity of investment and the cash-flow constraint.

The model is calibrated so that the benchmark equilibrium is the economic balance of the European Union in 2001(EU 15), assuming that the economy was then in a steady state.

\section{B Modeling economic impacts of natural disasters}

As comprehensively explained in Hallegatte et al. (2007a), modeling disaster consequences leads to several specific difficulties and requires the use of specific methods. Indeed, disasters mainly destroy the stock of productive capital and causes short-term disequilibrium that have to be taken into account. A natural modeling option to represent disasters is to consider that they reduce instantaneously the total productive capital $(K \longrightarrow K-\Delta K)$.

To avoid natural disaster impacts to be underestimated because of decreasing 
returns in the production function (see Hallegatte et al., 2007a), we modified the Cobb-Douglas production function by introducing a term $\xi_{K}$, which is the proportion of non-destroyed capital. This new variable $\xi_{K}$ is such that the effective capital is $K=\xi_{K} \cdot K_{0}$, where $K_{0}$ is the potential productive capital, which is the stock of capital in absence of disaster. The new production function is:

$$
Y=\xi_{K} \cdot f\left(L, K_{0}\right)=\xi_{K} \cdot A \cdot L^{\lambda} \cdot K_{0}^{\mu}
$$

With this new production function, a $x \%$ destruction of the productive capital reduces production by $x \%$.

The replacement of the productive capital $K$ by the two new variables $K_{0}$ and $\xi_{K}$ makes it necessary to modify the modeling of investment and to introduce the distinction between regular investments, carried out to increase the production capacity, and reconstruction investments that follow a disaster. Denoting $I_{n}$ the investments that increase the potential capital $K_{0}$, and $I_{r}$ the reconstruction investments that increase $\xi_{K}$, we have:

$$
\begin{aligned}
& \frac{\partial K_{0}}{\partial t}=\frac{-1}{\tau_{d e p}} K_{0}+\frac{I_{n}}{\xi_{K}} \\
& \frac{\partial \xi_{K}}{\partial t}=\frac{I_{r}}{K_{0}}
\end{aligned}
$$

Since reconstruction investments have higher returns, we could assume that, when $\xi_{K}<1$, investments are first devoted to replace the destroyed capital. Short-term constraints, however, play an important role in disaster aftermaths, by slowing down the reconstruction process. To capture how these constraints may impact the pathways back to the equilibrium, we bounded by $f_{\max }$ the 
fraction of total investment that reconstruction investments can mobilize.

$$
\left\{\begin{array}{l}
I_{n}=I-I_{r} \\
I_{r}= \begin{cases}\operatorname{Min}\left(f_{\max } \cdot I,\left(1-\xi_{K}\right) \cdot K_{0}\right) & \text { if } \xi_{K}<1 \\
0 & \text { if } \xi_{K}=1\end{cases}
\end{array}\right.
$$

A value $f_{\max }=5 \%$ means that the economy can mobilize about $1 \%$ of GDP per year for the reconstruction i.e. about 90 billion of euros per year for EU-15. 


\section{Notes}

${ }^{1}$ We assume that the economy was then on a balanced growth pathway. Obviously, the economy of EU-15 was not on a balance growth pathway in 2001; but this approximation is made acceptable by the weak sensitivity of our results to small differences in the base year equilibrium.

${ }^{2}$ This simple modeling is supposed to account for improvements in production organization.

${ }^{3} \mathrm{~A}$ formal demonstration of the possibility of constructing such an aggregate capital, when using a constant-return production function, is provided by Fisher (1965).

${ }^{4}$ Of course, an infinite scrapping time means here a scrapping time large compared with the time horizon considered in the analysis.

${ }^{5}$ As an example, Guatemala suffered from Hurricane Mitch in 1998, from 3 years of drought from 1999 to 2001, and from hurricane Michele in 2001, and this series of events severely inhibited economic development. In the same region, the Honduran prime minister said that the single hurricane Michele in 2001 "put the country's economic development back 20 years".

${ }^{6}$ The goods inventory should be interpreted as the difference with an equilibrium value. A positive value indicates temporary overproduction; a negative value indicates underproduction.

${ }^{7}$ The existence of this stock is justified both by the preference for liquidity and precautionary savings, and by practical constraints, since this stock of money is needed to carry out the economic transactions. 
${ }^{8}$ In NEDyM the share dividends encompass all investment benefits: dividends, revenues from bonds, sales of assets, capital gains, spin-offs to shareholders, repurchase of shares.

${ }^{9}$ Other economic regimes are possible, for example a "managerial economy" in which the priority is given to investments: managers redistribute then to shareholders the amount of funds available when all profitable investments have been funded. 


\section{List of Figures}

1 Productivity growth and GDP changes in response to a disaster destroying capital amounting for $2.5 \%$ of GDP under the three hypotheses: exogenous technical change (EX); endogenous technical change with perfect productivity effect (EN); and endogenous technical change with imperfect productivity effect with $\chi=0$ (IM-0).

2 GDP changes in response to a series of disasters in the three hypotheses: exogenous technical change (EX); endogenous technical change with perfect productivity effect (EN); and endogenous technical change with imperfect productivity effect with $\chi=0$ (IM-0).

3 GDP changes in response to a disaster destroying capital amounting for $2.5 \%$ of GDP, in the hypothesis of endogenous technical change with quality-speed trade-off, with $\chi$ equal to $0,0.4$, and $1.0(\mathrm{QS})$, and in the hypothesis of the endogenous technical change with perfect productivity effect (EN) hypothesis.

4 GDP changes in response to a series of disasters in the quality-speed hypothesis, with 3 values of $\chi: 0.0,0.4$ and 1.0; and for the the endogenous technical change with perfect productivity effect (EN) hypothesis. GDP losses in the EN and QS-1.0 hypotheses can hardly be distinguished.

5 average GDP change (over 200 years) due to extreme events, as a function of the probability and intensity of the extreme events. In each simulation, the probability and the mean cost of disasters are multiplied by $\alpha$ with respect to the observed distribution. $f_{\max }$ is always at $5 \%$. 

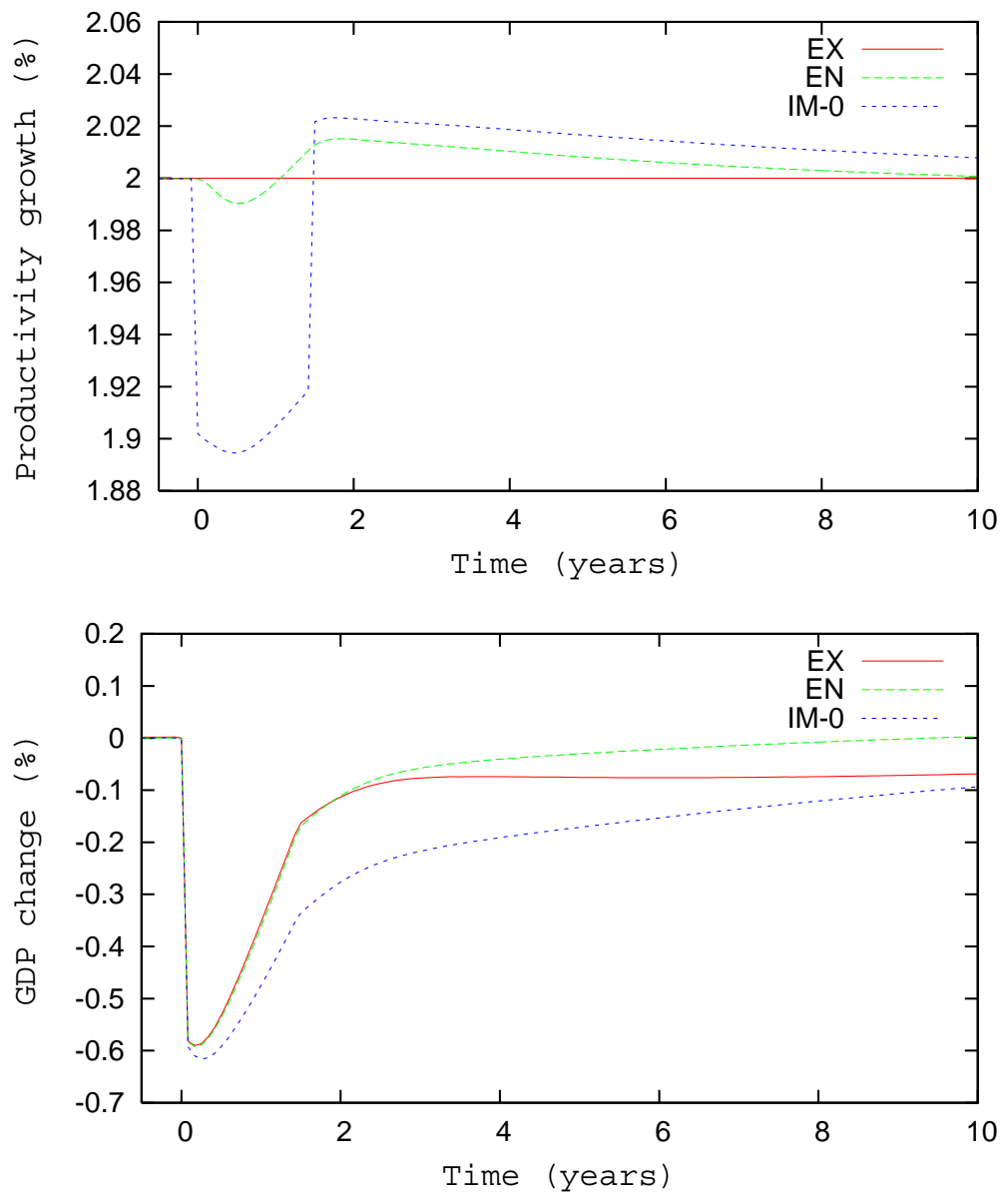

Fig. 1. Productivity growth and GDP changes in response to a disaster destroying capital amounting for 2.5\% of GDP under the three hypotheses: exogenous technical change (EX); endogenous technical change with perfect productivity effect (EN); and endogenous technical change with imperfect productivity effect with $\chi=0$ (IM-0). 


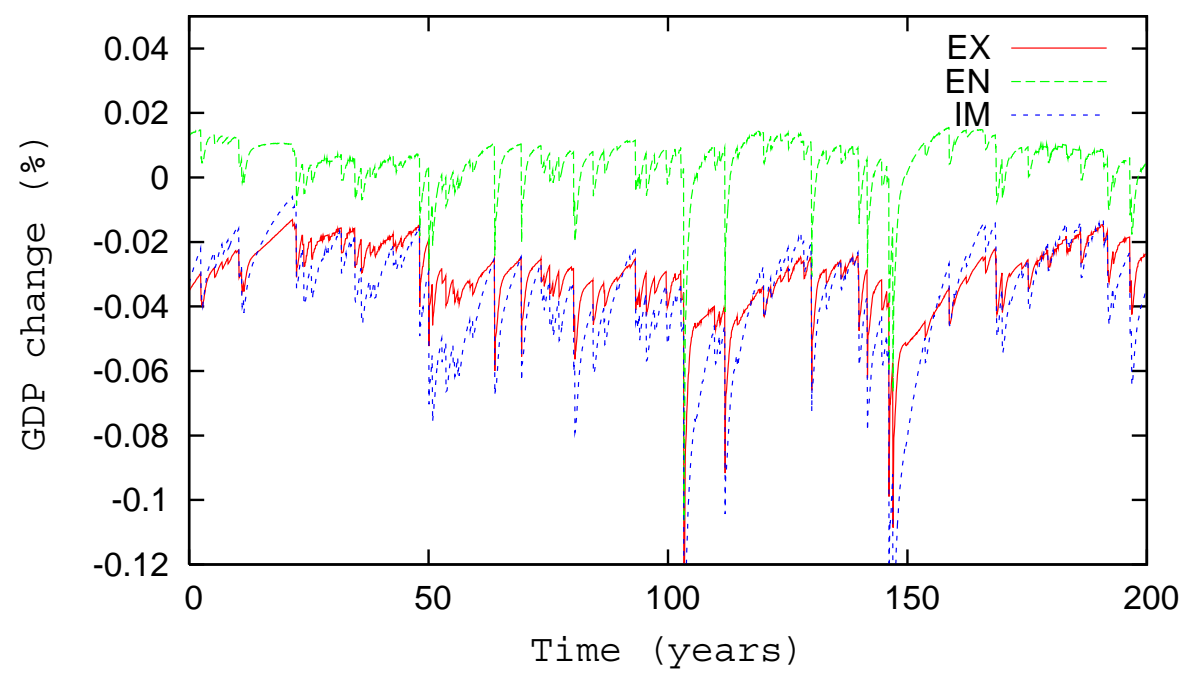

Fig. 2. GDP changes in response to a series of disasters in the three hypotheses: exogenous technical change (EX); endogenous technical change with perfect productivity effect (EN); and endogenous technical change with imperfect productivity effect with $\chi=0$ (IM-0). 


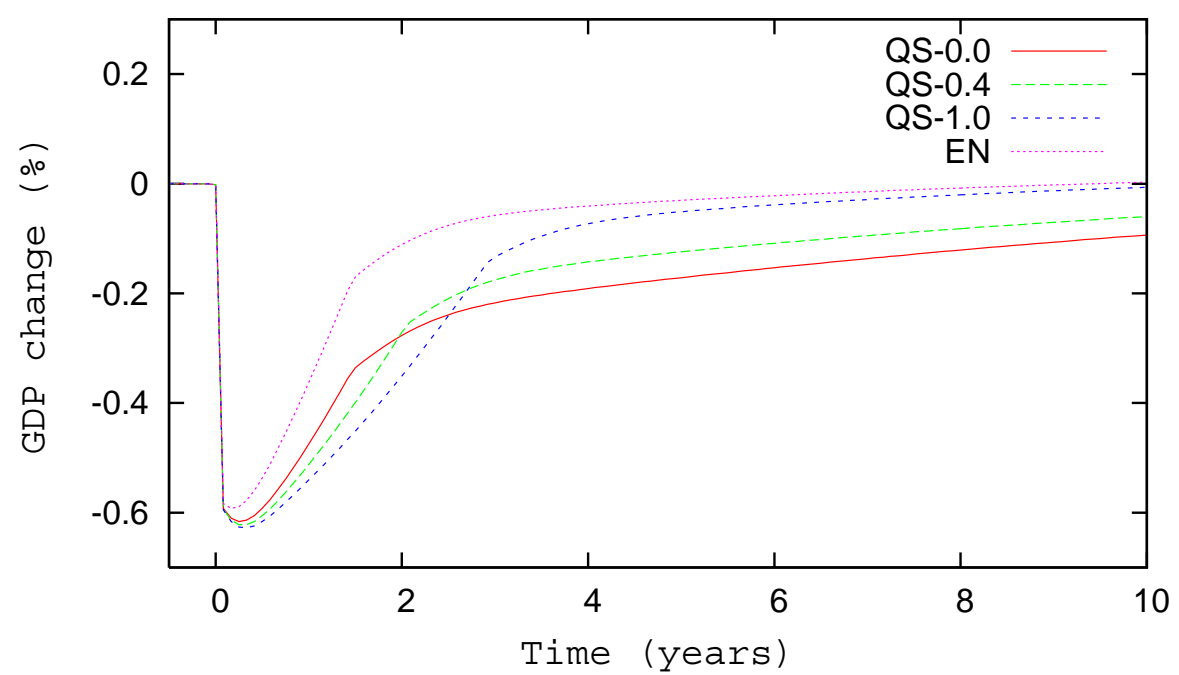

Fig. 3. GDP changes in response to a disaster destroying capital amounting for $2.5 \%$ of GDP, in the hypothesis of endogenous technical change with quality-speed trade-off, with $\chi$ equal to $0,0.4$, and 1.0 (QS), and in the hypothesis of the endogenous technical change with perfect productivity effect (EN) hypothesis. 


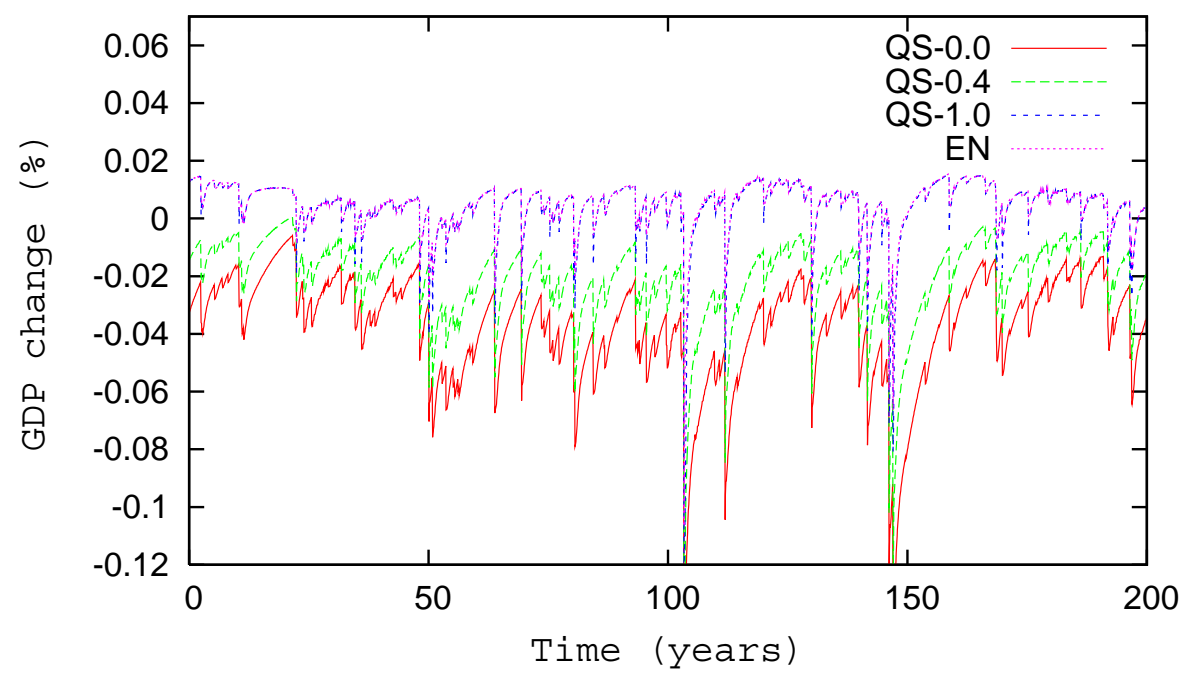

Fig. 4. GDP changes in response to a series of disasters in the quality-speed hypothesis, with 3 values of $\chi: 0.0,0.4$ and 1.0; and for the the endogenous technical change with perfect productivity effect (EN) hypothesis. GDP losses in the EN and QS-1.0 hypotheses can hardly be distinguished. 


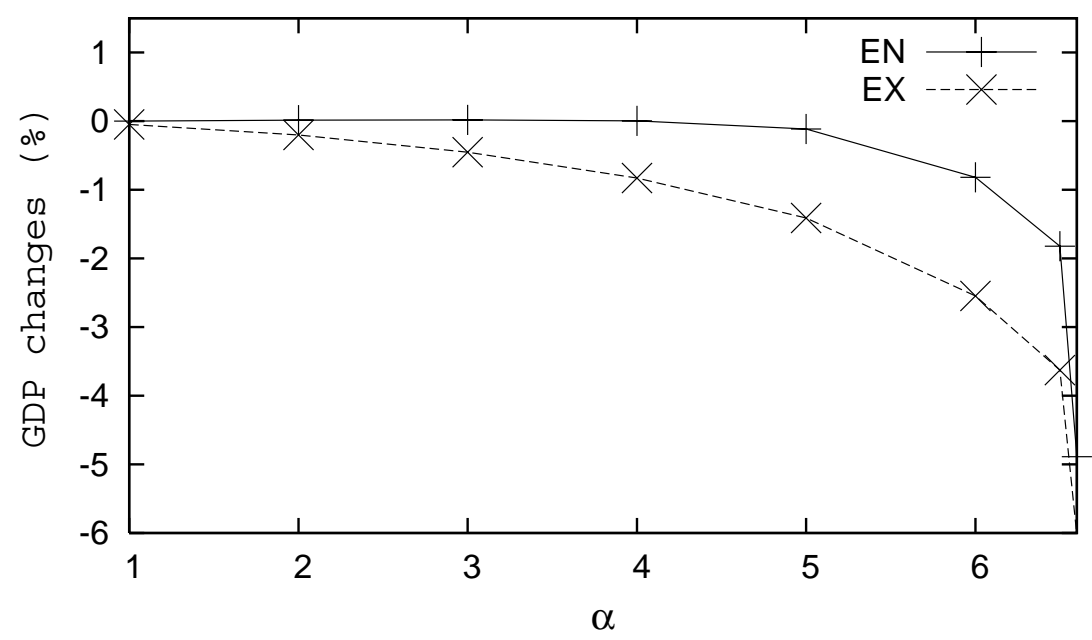

Fig. 5. average GDP change (over 200 years) due to extreme events, as a function of the probability and intensity of the extreme events. In each simulation, the probability and the mean cost of disasters are multiplied by $\alpha$ with respect to the observed distribution. $f_{\max }$ is always at $5 \%$. 